\title{
COLECISTECTOMIA LAPAROSCÓPICA EM UM PACIENTE COM DUCTO CÍSTICO DUPLO
}

\section{LAPAROSCOPIC CHOLECYSTECTOMY INA PATIENT WITH DUPLICATED CYSTIC DUCT}

\author{
Julio Cezar Uili Coelho, TCBC-PR ${ }^{1}$ \\ Carolina Gomes Gonçalves ${ }^{2}$ \\ Daniel Francisco Mello ${ }^{3}$
}

\section{INTRODUÇÃO}

Apesar das anomalias do trato biliar serem comuns, a duplicação da vesícula biliar é uma anomalia congênita rara, cuja incidência é cerca de $1: 3800^{1-5}$. A grande maioria dos casos são achados ocasionais de autópsia ou intra-operatórios. O achado operatório de duplicação da vesícula com dois ductos císticos pode levar a dificuldade diagnóstica ou lesão iatrogênica da via biliar principal. O objetivo do presente estudo é relatar um caso de colecistectomia laparoscópica em paciente com duplicação de vesícula biliar e do ducto cístico e salientar a importância do diagnóstico diferencial de lesão iatrogênica da via biliar principal.

\section{RELATO DO CASO}

Paciente masculino, 34 anos, branco, apresentou-se com história de dor abdominal de moderada intensidade em hipocôndrio direito, sem febre, icterícia ou colúria. Relatava história de várias crises de dor em hipocôndrio direito, com início há seis anos, sendo que em um dos episódios apresentou icterícia discreta. O exame físico era normal, exceto pela presença de dor moderada à palpação de hipocôndrio direito $\mathrm{O}$ sinal de Murphy estava ausente. Os exames laboratoriais da admissão eram transaminase glutâmico oxalacética de 86 , transaminase glutâmico pirúvica de 36 , fosfatase alcalina de 87 e bilirrubina total de 0.32 .
A ultra-sonografia revelou vesícula biliar com múltiplos pequenos cálculos e com paredes espessadas.

O paciente foi submetido à colecistectomia laparoscópica e no ato operatório foi observada vesícula biliar de aspecto inflamatório crônico, com paredes bastante espessadas e aderências firmes. Foi realizada dissecção cuidadosa do hilo, com identificação de ducto cístico que era calibroso. A via biliar principal e sua junção com o ducto cístico foram identificadas. A artéria cística também foi isolada. Após a secção do ducto cístico observou-se que este ducto apresentava-se duplicado. Para excluir lesão da via biliar principal foi realizada identificação dos ductos hepáticos comum, direito e esquerdo. A colangiografia através de um dos ductos císticos não evidenciou outras anomalias. A vesícula biliar foi dissecada do seu leito e retirada através do umbigo. A abertura da vesícula evidenciou ducto cístico duplicado com septação completa da vesícula biliar (Figura 1). O paciente teve boa evolução, e recebeu alta no primeiro dia pós-operatório. Os achados cirúrgicos foram confirmados pelo exame anatomo-patológico.

\section{DISCUSSÃO}

Há vários tipos de duplicação de vesícula biliar, sendo a maioria deles muito $\operatorname{raros}^{(1,2,5)}$. Podem ser classificados em duplicações verdadeiras e em vesículas acessórias (Figura 2).

1. Professor Titular e chefe da Disciplina de Cirurgia do Aparelho Digestivo da Universidade Federal do Paraná.

2. Residente do Serviço de Cirurgia Geral do Hospital Nossa Senhora das Graças de Curitiba.

3. Acadêmico de Medicina da Universidade Federal do Paraná. 


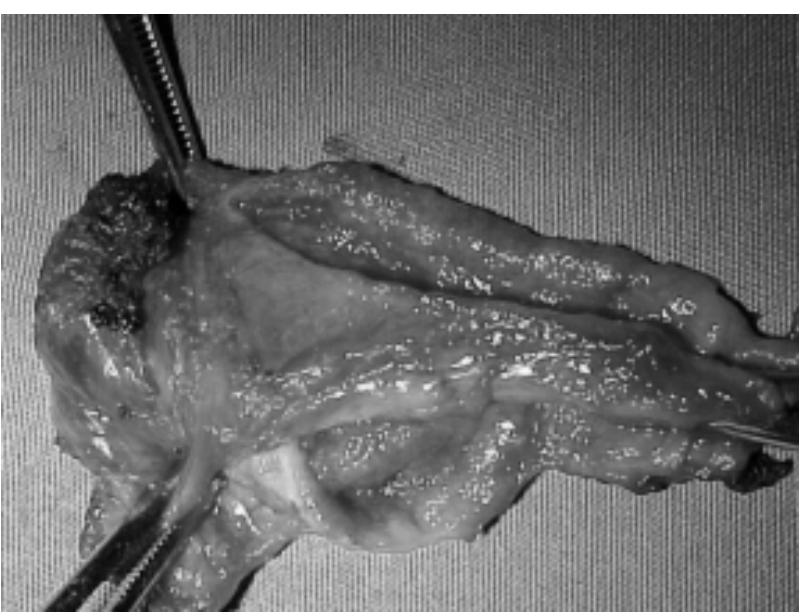

Figura 1 - Vesícula biliar aberta mostrando a septação interna completa e o ducto cístico duplicado.

Duplicações verdadeiras são aquelas que ocorrem a partir da separação do primórdio vesicular durante a sexta semana de desenvolvimento embrionário. A classificação encontrada divide os padrões de duplicação de vesícula biliar verdadeira em "V" e "Y", sendo "V" aquela vesícula com aparência externa normal, com septo longitudinal interno, e "Y" a presença de duas vesículas separadas com um ducto cístico comum (duplicação em "V" ou bilobada). As

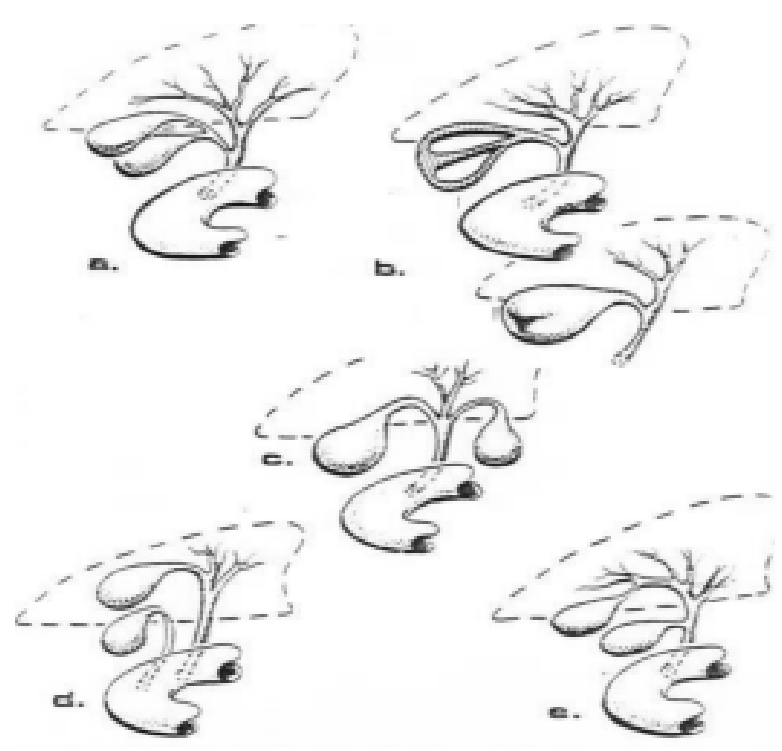

Figura 2 - Duplicação Verdadeira da vesícula biliar: a) tipo " $Y$ "; b) septo interno ou externo dividindo a vesícula, tipo " $V$ "; c) ductular ou tipo " $H$ "; d) duodenal; e) trabecular - quando o ducto acessório entra no ducto intra-hepático direito. (De Janson e Gulliver ${ }^{2}$ ) vesículas acessórias, por outro lado, originam-se de dois primórdios vesiculares distintos, e possuem ductos individuais. Estas podem ser divididas em: duplicação em "H", duplicação trabecular e o tipo duodenal, sendo a "H"duas vesículas separadas, com ductos císticos distintos que se unem antes de sua junção com o ducto hepático comum. A trabeculada é aquela em que o ducto cístico acessório termina num ramo do ducto hepático direito, dentro do fígado e o tipo duodenal apresenta vesícula acessória em que o ducto cístico desemboca diretamente no duodeno ${ }^{1-4}$.

$\mathrm{O}$ paciente relatado neste caso apresentava uma vesícula de padrão intermediário entre $\mathrm{V}$ e Y, pois a vesícula estava separada em duas por um septo interno e cada compartimento possuía um ducto cístico próprio, os quais externamente pareciam como um ducto cístico comum.

O diagnóstico pré-operatório de duplicação da vesícula biliar é sempre muito difícil, uma vez que a sintomatologia é indistinguível dos casos de vesícula única ${ }^{3}$. Pode ser, entretanto, um achado incidental, após colangiografia endoscópica retrógrada pré-operatória. A vesícula dupla pode ser detectada durante um estudo ultra-sonográfico cuidadoso, mas outras doenças podem ter características idênticas ao exame, como divertículos ou dobraduras da vesícula, bandas vasculares, cistos coledocianos ou adenomiomatose focal. A cintilografia com derivados do ácido iminodiacético e a colecistografia oral podem dar resultados falsos negativos, nos casos de obstrução de apenas um ducto cístico, devendo isto ser considerado nos casos em que os sintomas e sinais sugerem fortemente colecistite aguda. A colangiografia endoscópica retrógrada provavelmente é o exame mais preciso, uma vez que o ducto cístico pode ser visualizado diretamente ${ }^{3-5}$.

No caso relatado o único exame de imagem era a ultra-sonografia, que não evidenciou qualquer sinal que sugerisse a presença de duplicação de vesícula biliar.

O diagnóstico preciso de duplicação da vesícula biliar deve ser estabelecido no ato operatório para excluir a ocorrência de lesão da via biliar principal. A presença de dois ductos biliares indica mais frequientemente uma lesão iatrogênica da via principal do que uma anomalia congênita das vias biliares. Para o diagnóstico diferencial preciso o cirurgião deve realizar colangiografia per-operatória para certificarse da integridade da via biliar principal. $\mathrm{O}$ exame da vesícula no final da operação é essencial para estabelecer o diagnóstico de certeza. 


\begin{abstract}
Our objective is to report a case of laparoscopic cholecystectomy in a patient with duplicated cystic duct. A 34 year old male presented with episodic pain in the upper rigth quadrant of the abdomen. Murphy's sign was not present. Ultrassonography showed gallbladder with multiple calculi and a thickened wall. At laparoscopic cholecystectomy, a duplicated cystic duct was found. Careful dissection and intraoperative cholangiography were performed to rule out common bile duct injury.
\end{abstract}

Key Words: Laparoscopic cholecystectomy; anomaly cystic duct; double cystic duct; intraoperative cholangiography.

\section{REFERÊNCIAS}

1. Jannke HA, Aleixo A, Hammes EL. Duplicação de vesícula biliar-Relato de caso. Rev Bras Cir 1990;80:61-62.

2. Janson JA, Gulliver D, Cotton PB. Choledocholithiasis and a double gallbladder. Gastrintestinal Endoscopy 1992;38:377-9.

3. Lobo EJ, Herbella FAM, Goldenberg A, et al. Laparoscopic cholecystectomy in a patient with duplicated cystic duct. Sur Laparosc Endosc Percutan Tch 2000;10:326-328.

4. Momiyama T, Souda S, Yoshikawa Y, et al. Injury to a duplicated cystic duct during laparoscoic cholecystectomy. Surgical Laparosc Endosc 1996;6:315-7.
5. Özgen A, Akata D, Arat A, et al. Gallbladder duplication: imaging fidings and differential considerations. Abdom Imaging 1999; 24:285-8.

Endereço para Publicação:

Dr. Júlio Coelho

Rua Bento Viana, 1140 - Ap 2002

80240-000 - Curitiba-PR

Tel (Fax): (41) 322-3789 